\title{
On the reliability of linear elastic analyses of historical masonry buildings: A case study
}

Received (in revised form): 3rd November, 2006

\begin{abstract}
Alberto Taliercio PhD
is full professor of Structural Mechanics at the Faculty of Civil Engineering, Technical University (Politecnico) of Milan, Italy. He was also 'Professeur chargé de cours' at the Ecole Polytechnique, Paris, from 1998 to 2001. He has authored more than 80 scientific papers and three books. His main research interests are: (a) nonlinear mechanics of concrete and masonry; (b) nonlinear and ultimate behaviour of fibre-reinforced composite materials; and (c) structural optimisation.
\end{abstract}

\section{Luigia Binda}

is full professor of Diagnosis, Strengthening and Restoration of Historic Buildings at the Faculty of Architecture, Technical University (Politecnico) of Milan, Italy. She has authored nearly 430 scientific papers. Her main research topics are: (a) in situ and laboratory experimental investigation for the evaluation of the mechanical and physical damage in masonry structures; (b) limit analysis of masonry structures; (c) effects of the chemical-physical alteration on the mechanical behaviour and the durability of brick masonry; (d) long-term behaviour of masonry under constant and cycling loads; and (e) investigation and modelling of stone masonry historic buildings in seismic areas. She is currently a member of RILEM (nominated Honorary member in 2006), the American Masonry Society (TMS - nominated TMS Fellow in 2006), the British Masonry Society, and several committees of the Italian Ministry of Cultural and Environmental Resources. Presently, she is Chairwoman of RILEM TC SAM and Convener of Cluster E of RILEM TAC.

Correspondence: Alberto Taliercio, Department of Structural Engineering, Politecnico di Milano, Piazza Leonardo da Vinci 32. 20133 Milan, Italy; Tel: + 3902239942 41; Fax: + 3902239942 20; E-mail: alberto.taliercio@polimi.it

\begin{abstract}
A finite element model was developed to analyse the Byzantine Basilica of San Vitale in Ravenna (Italy); modelling is intended to help understanding the origin of a diffused crack pattern in the building. In the structural analyses, account was taken of the permanent loads and the seasonal thermal changes. Owing to the complexity of the geometric model, a simplified (linearly elastic, isotropic) constitutive law had to be assumed to keep the computing time within reasonable limits. Accordingly, the adopted constitutive law cannot fully explain the surveyed crack pattern, which is influenced by the brittleness and the anisotropy of the constituent materials; thus, the performed analyses constitute only a first step towards the understanding of the structural behaviour of the Basilica. It is shown, however, that the self-weight alone is largely responsible for the current state of damage in the Basilica. The numerically predicted seasonal change in displacements agree fairly well with the measurements of a monitoring network taken every six months, which proves the reliability of the finite element model.
\end{abstract}

Journal of Building Appraisal (2007) 2, 301-312. doi:10.1057/palgrave.jba.2950051

\section{Keywords:}

masonry, Byzantine Basilica, finite elements, survey, settlements, cracking

\section{INTRODUCTION}

The Basilica of San Vitale in Ravenna, Italy, dates back to the 6th century AD and is one of the most important Byzantine buildings in Europe. The church as it appears today (Figure 1) is the outcome of a number of extensions, demolitions and restorations. For 


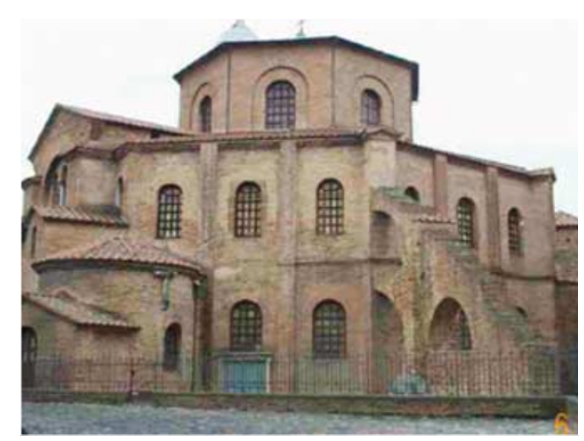

Figure I: View of the Basilica of San Vitale (courtesy of Mrs Anna Pasta)

a detailed description of the changes in the layout of the building during the centuries and the strengthening works carried out in the past century, readers are referred to Binda et al. (1995). One of the most significant works, dating back to the 11th and 12th centuries, is the replacement of the former timber floors over the ambulatory and the women's gallery with 'toric' masonry vaults provided with lunettes: the thrust exerted by the new vaults endangered the statics of the building to such an extent that two buttresses had to be added (Figure 2a: BT1 and BT2).

During the 19th and the 20th centuries, massive interventions were made with the aim of restoring 'the original lines' of the building, including the demolition of several chapels. A plan of the present-day building is shown in Figure 2. The previously mentioned works, along with subsidence of the soil in the Ravenna region, are likely to have strongly affected the static of the building which was found to be in danger at the beginning of the 20th century. Accordingly, steel rods were fit to connect several pairs of pillars (Figure 2: PE2-P2, PE3-P3, PE5-P5 and PE7-P7) and to prevent cracks from opening further. In addition, some parts of the Basilica were restored or reconstructed.

Although these restoration works brought some relief to the building, the Basilica still has to be constantly monitored to detect its movements and prevent possible new faults developing. In 1998, a monitoring system was installed to survey the differential displacements at a number of benchmarks located both inside and outside the Basilica (Figure 3) and are measured, as a rule, every three months (February, May, August and November).

It is clear that an understanding of the current potential damage to the building should take into account not only the current loads and ground settlements, but also the complex constructive changes experienced by the Basilica during the previous centuries. Although this is not done in the present study, it should be kept in mind when interpreting the crack pattern in the building.

This paper deals with the structural analysis of the Basilica using a refined finite element model within the framework of linear elasticity, and discusses the consequences of this simplifying assumption in terms of the reliability of the numerical results obtained.

\section{A BRIEF DESCRIPTION OF THE BUILDING}

For a detailed description of the present-day building, readers are referred to Taliercio and Binda (2006). The Basilica consists of two concentric octagonal prisms (Figure 2): the radii of the cylinders circumscribing the inner and the outer prisms are about 10 and $19.75 \mathrm{~m}$, respectively. The inner prism ends with a drum-dome system supported by eight pillars of irregular cross-section (P1-P8 in Figure 2a). The drum reaches a height of 

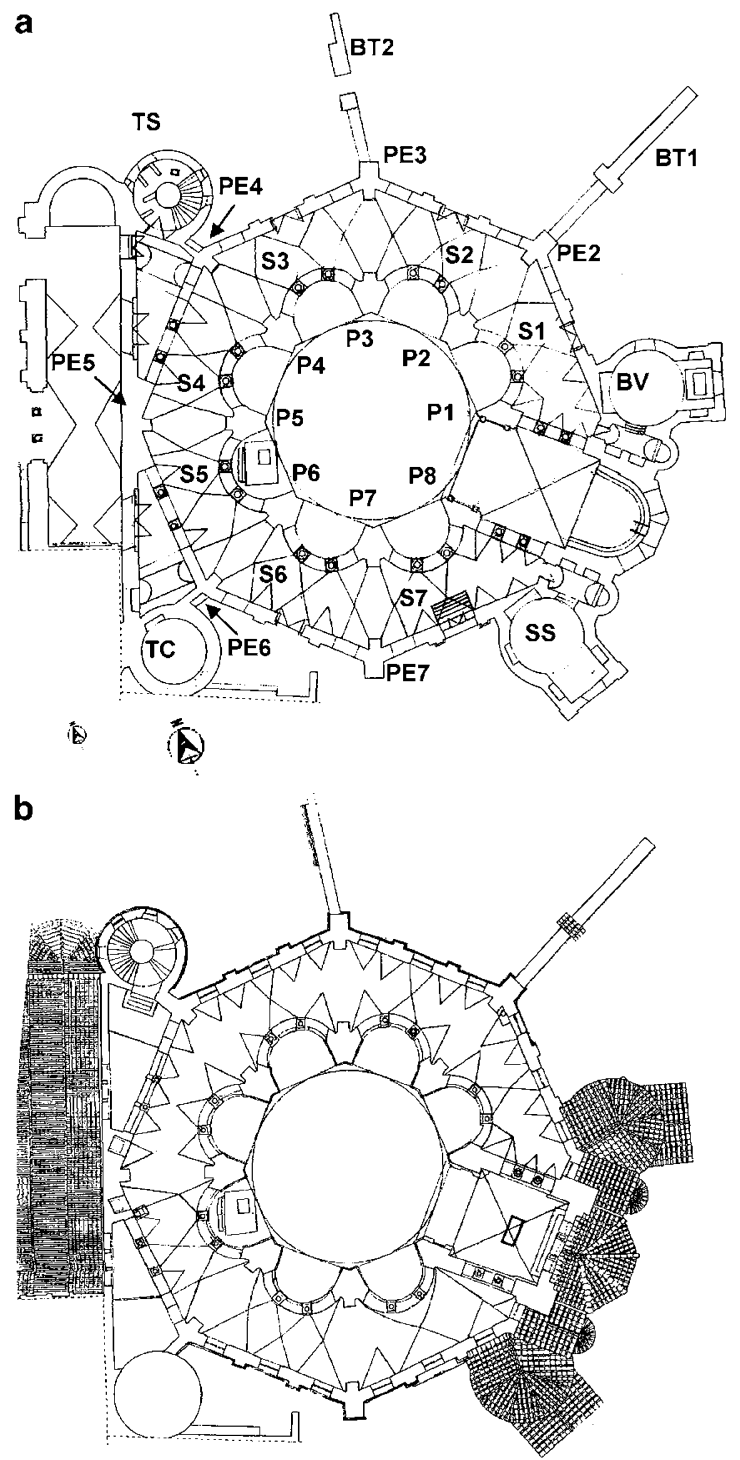

Figure 2: Present-day plan of the Basilica: (a) ground floor; (b) first floor.The projections of the vaults are also shown. BT: buttresses, P/PE: pillars, TC: southern tower,TS: northern staircase tower, S: sector, SS/BV: sacristies

$26.7 \mathrm{~m}$, whereas the extrados of the dome reaches $29 \mathrm{~m}$ at the crown. The walls of the outer prism are about $16 \mathrm{~m}$ high and $0.97 \mathrm{~m}$ thick. The outer prism consists of two levels: the ambulatory and women's gallery, which are both covered by toric vaults; the floor of the women's gallery is at about $9 \mathrm{~m}$. At the corners of the outer octagon, six pillars with trapezoidal cross-section of different sizes are visible (PE2-PE7 in Figure 2a).

The two octagons are linked through a system of semicircular exedras overlooked by windows with three lights supported by marble columns. At the level of the women's gallery, the two octagons are connected by semicircular arches, whose springers are supported by the corner pillars of the outer wall and by the inner pillars (Figure 2b). The dome and outer octagon are covered by wooden beams.

A presbytery and apse are located to the east side of the church (Figure 2a). The presbytery is surmounted by a cross vault and the apse by a half-dome. The apse 

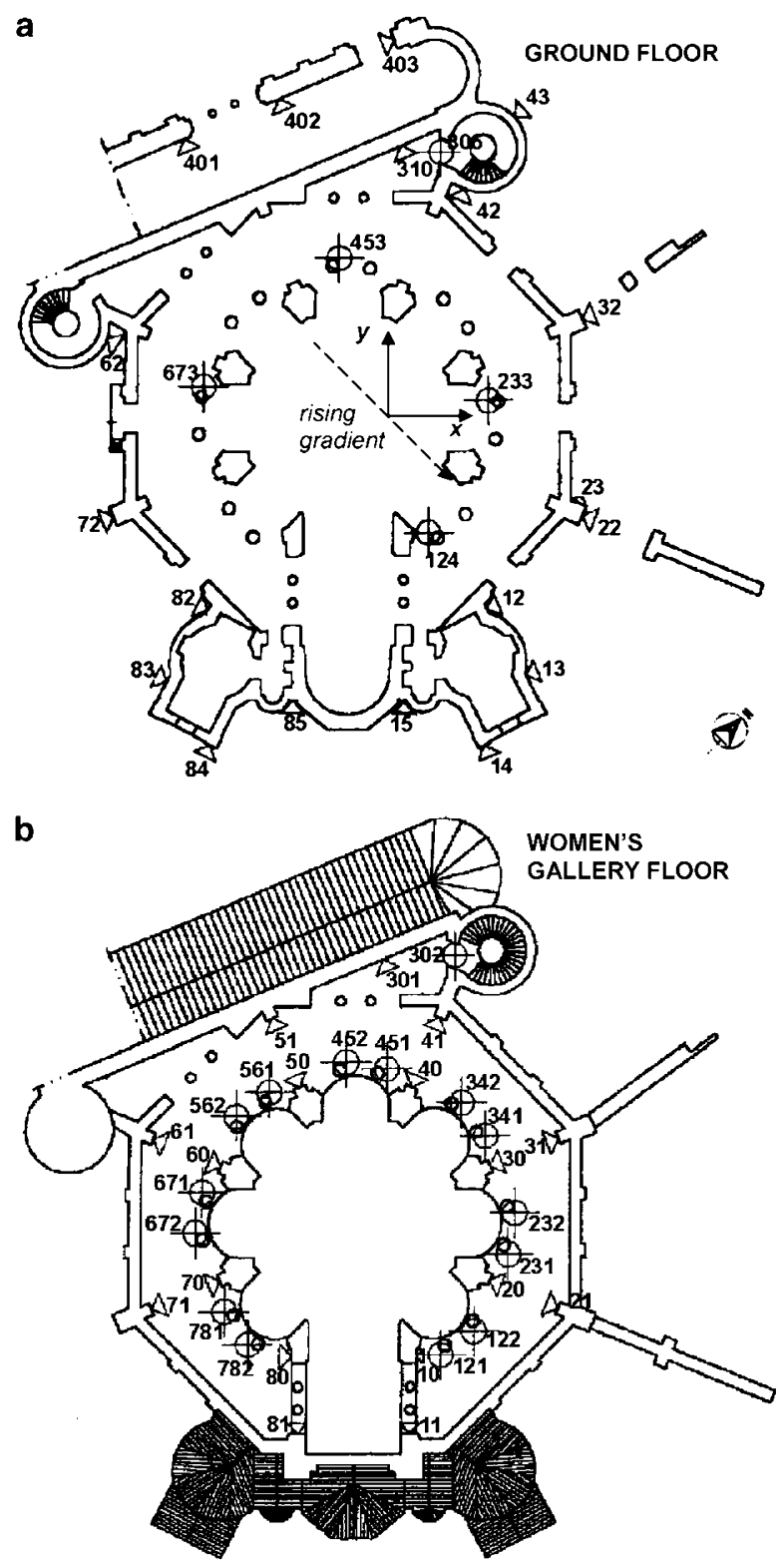

$\oint$ benchmarks at ground level $\Delta$ wall-mounted benchmarks

Figure 3: Numbering, location and type of the benchmarks in the Basilica (a) at the ground floor and (b) at the women's gallery level

is flanked at both sides by two sacristies endowed with semicircular chapels, covered by masonry domes (SS and BV in Figure 2a). The narthex is covered by a barrel vault provided with lunettes and is connected with the outer octagon of the church at point PE5. Two triangular-shaped vestibules are located between the Basilica and narthex and are contiguous to the two towers (TS and TC in Figure 2a). The southern tower (TC), which is nearly $36 \mathrm{~m}$ high, was converted into a bell-tower, while the northern staircase tower (TS) is shorter at $14.60 \mathrm{~m}$. On the north side, two pillars prop on flying buttresses (BT1 and BT2 in Figure 2a), which were built during the 11th and 12th centuries.

Most of the walls and the inner pillars were built using brickwork dating back to the 6th century ('mattoni Giulianei'). The largest side of these bricks ranges between 0.33 
and $0.52 \mathrm{~m}$ at the outer side of the walls, whereas it is around $0.32 \mathrm{~m}$ inside the walls. The ratio of the shortest to the largest side is $2: 3$. The thickness of the bricks is about $40 \mathrm{~mm}$. Bricks are alternated with mortar joints of the same thickness (mortar-to-brick ratio $=1: 1$ ) (refer to Binda et al., 1999, for a discussion on the role of thick joints in ancient masonry). The same building technique is encountered in most of the original vaults except for the dome (see below); also the later vaults above the ambulatory and the women's gallery were built in the same way. Bricks of different size can be found, for example, in part of the narthex and the inner leaf of the dome lantern while other differences are due to restoration works. The vaults covering the outer octagon dates back to the beginning of the 20th century and are made of hollow bricks; they are topped by wooden trusses with a tile mantle, and most of the walls are solid. In the dome lantern, at sector S5, the wall consists of three leaves: the inner leaf being made of large, randomly cast pieces of brickwork, bound together by mortar.

The dome is made of spindle-shaped fictile tubes with a rough surface and embedded in mortar (see Mirabella-Roberti et al., 1995, for more details). The dome is covered by a pitched timber roof which was likely built around 1780 and consists of 16 evenly spaced main beams of square cross-section $(0.24 \mathrm{~m})$, and 16 secondary beams (two per side) constrained to the main ones. The framework then supports wooden boards on which $3 \mathrm{~mm}$ thick lead slabs are laid.

The columns are made of marble coming from quarries in Proconnesus (modern day Marmara in Turkey).

\section{NUMERICAL MODEL OF THE BASILICA}

The numerical model of the Basilica was created using a commercial finite element code (ABAQUS®, vers. 6.4). The geometry of the Basilica was defined as accurately as possible according to the available drawings (Deichmann, 1969-1976), photographs and the photogrammetric survey of sector S2 (Binda et al., 1995). The timber roofs were not modelled, but rather indirectly taken into account as dead load acting on the model. The same applies to the upper part of the bell-tower, about $20 \mathrm{~m}$ high, which enters the model as a uniform load acting upon the lower, discretised section. The brickwork filling a number of arches in the Basilica was disregarded so that only the bearing contribution of the arches was taken into account. According to Deichmann (1969-1976) an infill was cast between the drum and dome up to $0.30 \mathrm{~m}$ above the arches. In the present analyses, the loose infill was given an elastic modulus equal to $1 / 10$ of that of the surrounding brick masonry and a slightly lower unit weight.

The finite element model consists of 10-noded, bilinear strain tetrahedra. The finite elements employed allow for the possibility that pillars and walls are subjected to both in-plane compression and bending, which would make the vertical stresses vary almost linearly across the wall thickness. They also allow curved surfaces to be quite accurately modelled. The size of the elements was chosen so as to have two elements across the wall thickness: this allows the presence of niches in the walls (see Figure 2a) to be captured; thus, the average size of the elements is about $0.60 \mathrm{~m}$. The finite element mesh consists of 277,411 elements with a total of 4,923,037 nodes and is shown in Figure 4.

In the present study, all the materials forming the Basilica were supposed to be linearly elastic and isotropic. This is a rough approximation for brick masonry and fictile tubes which are macroscopically orthotropic. This approximation is partially due to the lack of information about the properties of the materials along different directions. Also, taking anisotropy into account would make the numerical model even more cumbersome. All 


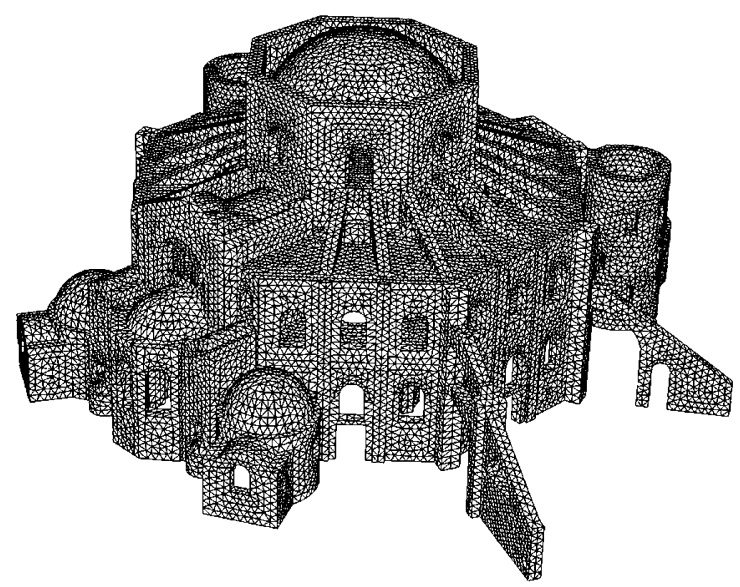

Figure 4: View of the finite element model of the Basilica

Table I: Material properties employed in the finite element analyses

\begin{tabular}{lllll}
\hline & Brick masonry & Infill & Dome masonry & Marble \\
\hline Elastic modulus (MPa) & 1,800 & 180 & 2,600 & 70,000 \\
Poisson's ratio & 0.1 & 0.2 & 0.2 & 0.3 \\
Density $\left(\mathrm{kg} / \mathrm{m}^{3}\right)$ & 1,600 & 1,400 & 1,450 & 2,750 \\
Coefficient of thermal expansion $\left({ }^{\circ} \mathrm{K}^{-1}\right)$ & $6 \mathrm{e}^{-6}$ & & & $4 \mathrm{e}^{-6}$ \\
\hline
\end{tabular}

the masonry walls and vaults were given the properties of the 'mattoni giulianei'. Also, the presence of some multi-leaf walls was disregarded, so that all the walls were regarded as homogeneous.

The thermo-mechanical properties employed in the numerical analyses are summarised in Table 1. The macroscopic elastic modulus of brick masonry was estimated through double flat-jack tests performed in a wall of sector S3. The unit weight was assessed from tests on samples of masonry taken from different locations. The elastic modulus of the dome masonry along the parallels was computed as a weighted average of the moduli of mortar (500-5,000 MPa) and fictile tubes (10,000 and 20,000 MPa). The remaining thermo-mechanical properties of the different materials, including marble, were taken from the literature. In particular, the materials, excluding marble, were given the same coefficient of thermal expansion, which is an average of the values found in the literature for masonry.

The numerical model allows also for the steel rods fitted between four pairs of pillars as shown in Figure 5. The connectors were given a diameter of $20 \mathrm{~mm}$ and an elastic modulus of $200,000 \mathrm{~N} / \mathrm{mm}^{2}$.

\section{STRUCTURAL ANALYSIS UNDER THE DEAD LOADS}

The first finite element analysis performed allows only for the permanent loads affecting the structure. The self-weight of the discretised structural elements was directly taken into account as a body force (see Table 1 for the values of the densities employed). The weights of the main nondiscretised parts of the building were converted into uniform pressures, $p$, acting perpendicularly upon the elements underneath and computed according to the unit weight of the relevant materials: this applies to the roof of the drum $\left(p=4.1 \mathrm{kN} / \mathrm{m}^{2}\right.$, acting on the top of the outer walls of the dome lantern - see also 
Lombardini, 1997), the roof of the external octagon $\left(p=3.25 \mathrm{kN} / \mathrm{m}^{2}\right.$, acting on the top side of the radial arches as shown in Figure 4), the roof of the presbytery $\left(p=3.03 \mathrm{kN} / \mathrm{m}^{2}\right.$, acting along its perimeter) and the nondiscretised part of the bell-tower $\left(p=322.4 \mathrm{kN} / \mathrm{m}^{2}\right)$. Note that the pressure matching the weight of the roof of the external octagon is not vertical: this is not deemed to be a critical approximation since the radial arches have an inclination of about $20^{\circ}$ to the horizontal plane. The wooden roofs of some minor components (sacristies, apsidal cells) were disregarded.

In the present analysis, the finite element model is perfectly constrained to the ground and no kinematic constraint is prescribed between the finite element model and the surrounding buildings.

\section{Results}

The main results of the finite element analyses are summarised in Figures 6-8. Figures 6 and 7 show contour plots of the maximum (tensile) principal stress in the building

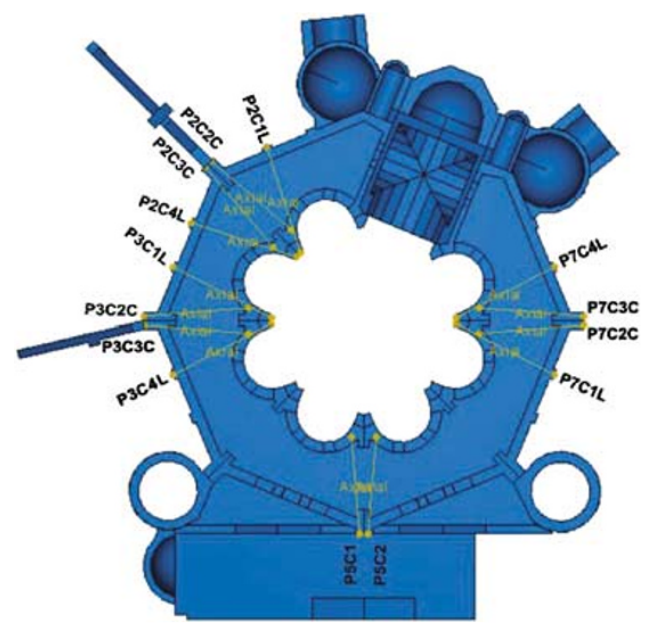

Figure 5: Location of the steel rods in the finite element model
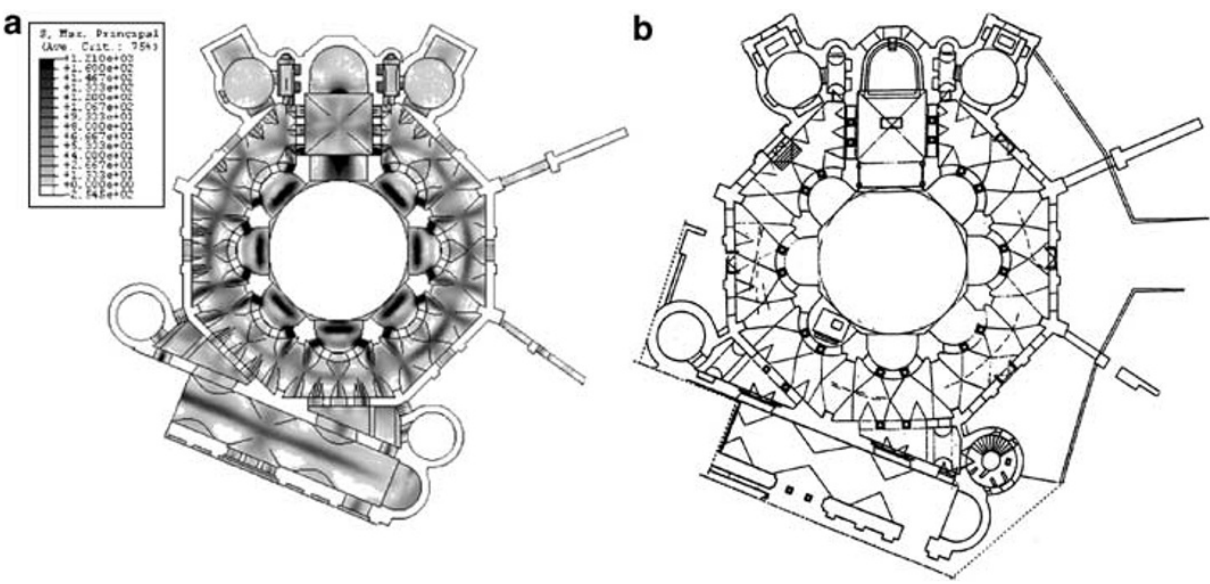

Figure 6: (a) Contour plots of the maximum (tensile) principal stress at the ground floor (view from below, values in $\mathrm{kN} / \mathrm{m}^{2}$ ); (b) crack pattern in the vaults of the ambulatory at the ground floor 
a

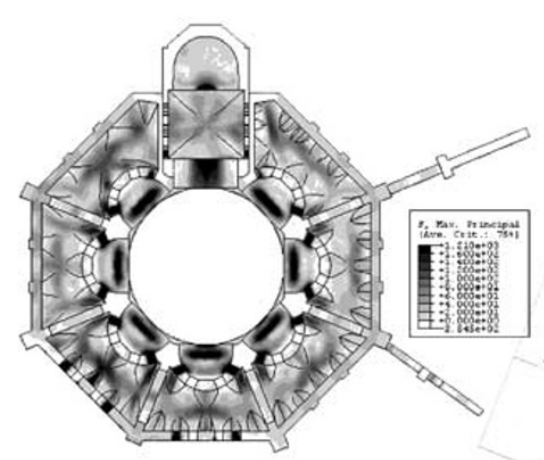

b

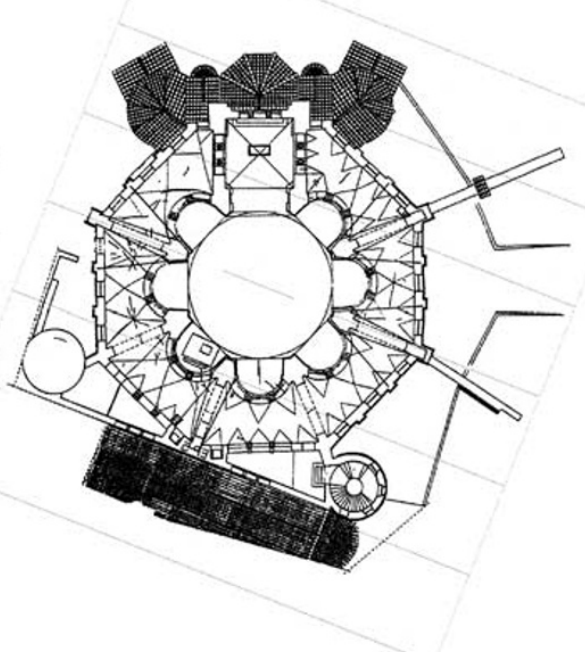

Figure 7: (a) Contour plots of the maximum (tensile) principal stress at the level of the women's gallery (view from below, values in $\mathrm{kN} / \mathrm{m}^{2}$ ); (b) crack pattern in the vaults of the women's gallery
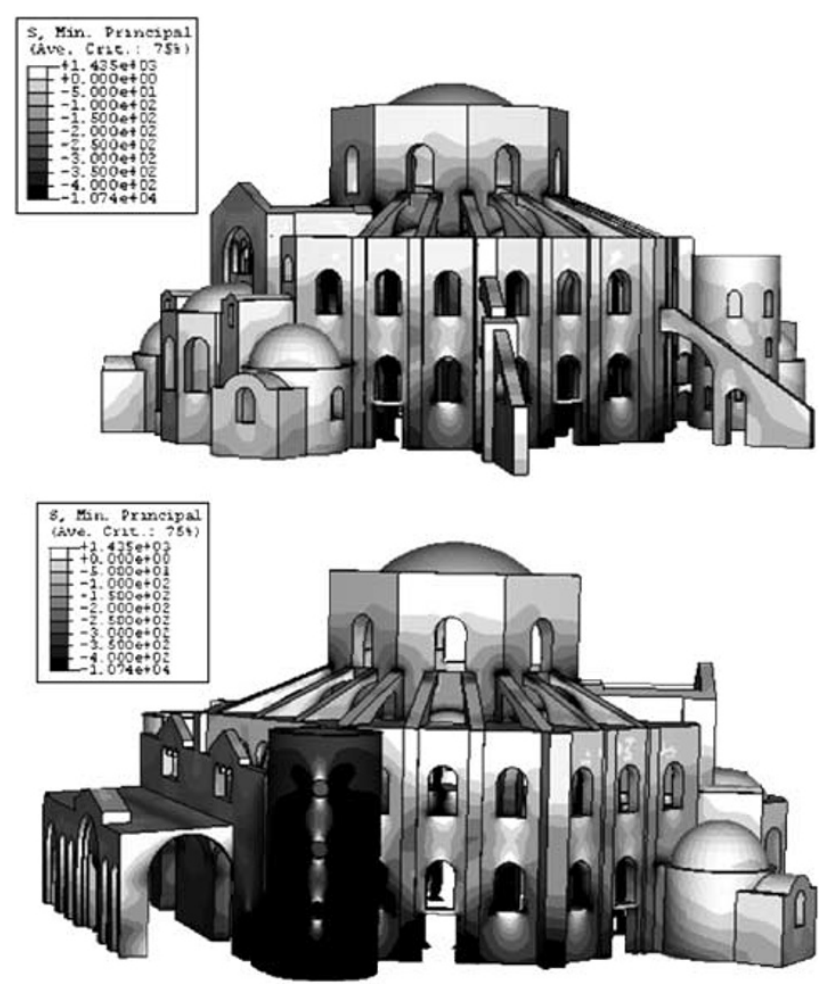

Figure 8: Contour plots of the minimum principal stress induced by the self-weight alone (in $\mathrm{kN} / \mathrm{m}^{2}$ ). Upper picture: north side; lower picture: south side

compared with the surveyed crack pattern in the Basilica, whereas Figure 8 shows contour plots of the minimum (compressive) principal stress. 
The tensile stresses are mainly localised in the vaults, the highest values (about $0.25-0.3 \mathrm{~N} / \mathrm{mm}^{2}$ ) being found at the crown of the exedras. At the ground floor, the most important cracks are found at the crown of sectors S2, S3, S4 and S7, while minor cracks exist in the lunettes. At the level of the women's gallery, the crack pattern is more widespread than at the ground floor. The zones subjected to tension are widespread along the crown of the entire vault with the maximum principal stress attaining values of the order of $0.03-0.07 \mathrm{~N} / \mathrm{mm}^{2}$ in most of the vaults. The zones where tension peaks were detected are the darkest ones in Figures $6 \mathrm{a}$ and $7 \mathrm{a}$. As the tensile strength of masonry can be assumed to be about $0.20 \mathrm{~N} / \mathrm{mm}^{2}$ (Lourenço, 2002), the intensity and the diffusion of the tensile stresses induced by the self-weight alone are sufficient to explain the existing cracks (Figures $6 b$ and $7 b$ ).

The maximum compressive stress has an average value of $-0.4 \mathrm{MPa}$ in the lower part of the building, except in the columns, while in the bell-tower higher values were encountered ( $-0.65 \mathrm{MPa}$ at the base; Figure 8$)$. As expected, the walls are subjected to in-plane compression and out-of-plane bending: the stresses at the base are of the order of $-0.2 \mathrm{~N} / \mathrm{mm}^{2}$ at the inner side and of $-0.3 /-0.4 \mathrm{~N} / \mathrm{mm}^{2}$ at the outer side, rising to $-0.45 /-0.55 \mathrm{~N} / \mathrm{mm}^{2}$ in the outer pillars and pilasters. The computed values were far below the compressive strength of brick masonry, which can be estimated to be about $4 \mathrm{~N} / \mathrm{mm}^{2}$. The same applies to the inner columns where compressions of the order of $-6.8 /-7.0 \mathrm{~N} / \mathrm{mm}^{2}$ are encountered at the ground floor, and of $-3.5 \mathrm{~N} / \mathrm{mm}^{2}$ at the level of the women's gallery. These values are much lower than the compressive strength of marble, which is around $100-140 \mathrm{~N} / \mathrm{mm}^{2}$ according to the literature. The columns are subjected to compression and bending so that tensile stresses are found in some pedestals.

It is worth noting that, according to the computations, the force exerted by the steel rods is extremely low: a reason for this is likely to be the linearly elastic constitutive law assumed for masonry, so that no loss in bearing capacity is accounted for. Actually, the rods were inserted to restrain the cracks, which appeared after the reorganisation of the Basilica at the end of the 19th century. To assess the effectiveness of the rods, the brittle behaviour of masonry has to be modelled, since their presence would be deemed to be unnecessary according to a perfectly elastic analysis.

\section{THERMAL ANALYSIS}

The reliability of the proposed finite element model could be assessed by comparing the numerically computed displacements with the measurements of the monitoring system installed in the Basilica in 1998 (Figure 3). The finite element model was prescribed a uniform increase in temperature of $+10^{\circ} \mathrm{C}$, which is the average seasonal thermal change from November to May recorded in the region of Ravenna. With a suitable change of scale the results obtained give the solution of the linear thermo-elastic problem for any other prescribed (uniform) change in temperature. The values of the coefficients of thermal expansion employed for the materials forming the building are listed in Table 1.

In Figure 9, the relative displacements of the benchmarks of the monitoring system at the level of the women's gallery between two consecutive measurements (May and November) are plotted and compared with the numerically computed displacements of nodes of the model close to the benchmarks. Regarding the data recorded in November, the agreement between the experimental and the numerical data is quite good: on average, the difference was of the order of $0.11 \mathrm{~mm}$, which is lower than the tolerance of the instruments employed in the survey. Also, note that the displacements of the benchmarks 


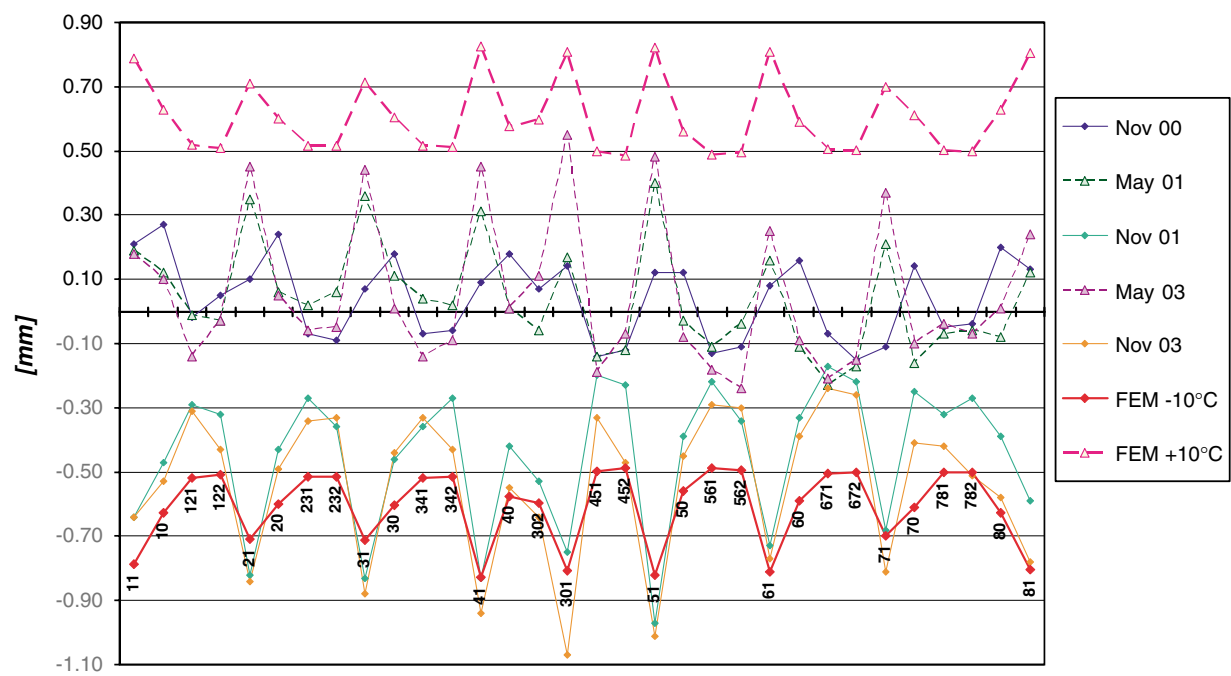

Figure 9: Women's gallery level: differential displacements of the benchmarks every six months, compared with the results of a finite element analysis with a uniform thermal variation of $\pm 10^{\circ} \mathrm{C}$

labelled $11,21,31$, etc are usually predicted more accurately than the remaining ones as these are the benchmarks mounted on the external pillars (Figure 3), where the temperature is likely to be closer to the external one. The remaining benchmarks are located in the inner part of the Basilica where thermal changes are likely to be different from the external environment.

The relative displacements recorded in May, contrary to those in November, were invariably overestimated by the numerical analysis, although the trend of the numerical plot shown in Figure 9 was similar to the experimental one.

Indeed, the differential displacements recorded every six months were affected by the subsidence of the ground below the Basilica. Assuming that the entire building undergoes a uniform vertical settlement (which is not exactly true, as a rotation of the buildings north-westwards has been observed - see also Figure 3a), by best fitting the displacements of the benchmarks, the average settlement every six months was found to be about $0.22 \mathrm{~mm}$. If this settlement is subtracted from the seasonal relative displacements, the plots shown in Figure 10 are obtained. Note that the displacements of all the benchmarks located on the outer pillars $(11,21,31$, etc) are again accurately predicted, while the remaining ones from the benchmarks inside the building are overestimated. If the seasonal change in temperature is decreased to $\pm 5^{\circ} \mathrm{C}$, a better prediction for these displacements is obtained (Figure 10).

In conclusion, the discrepancy between measurements and numerical predictions is likely to be attributable to the nonuniformity of the temperature throughout the Basilica. Also note that the coefficients of thermal expansion employed in the numerical analysis were simply taken from the literature, which might be an additional source for numerical errors. These coefficients could be more realistically estimated from tests on the constitutive materials.

\section{CONCLUDING REMARKS}

A refined finite element model of a Byzantine Basilica (San Vitale, Ravenna - Italy) was defined and employed to carry out linear elastic numerical analyses of the building 


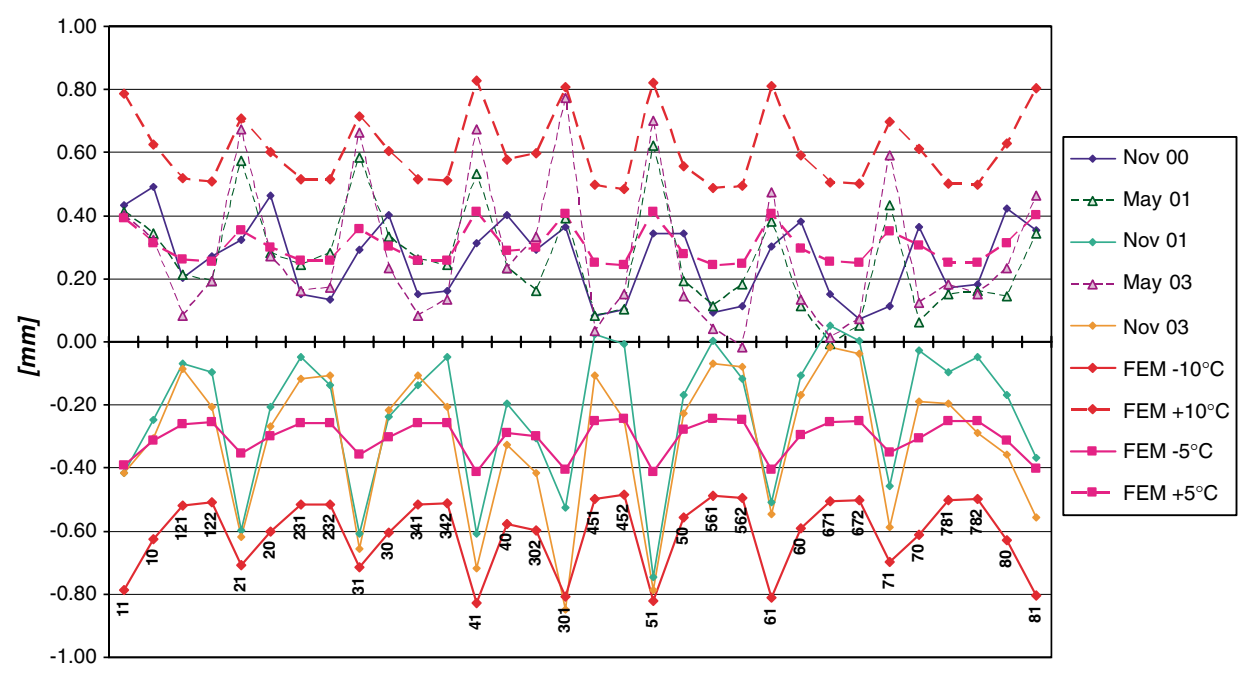

Figure 10: Women's gallery level: differential displacements of the benchmarks every six months net of the average rigid settlement of the building, compared with the results of finite element analyses with a uniform thermal variation of $\pm 10^{\circ} \mathrm{C}$ and $\pm 5^{\circ} \mathrm{C}$

to investigate the effects of the permanent loads and seasonal thermal changes. The reliability of the model could be assessed by comparing the differential displacements of a number of benchmarks monitored over six months with the numerically predicted one. The presence of most of the existing cracks can be explained by accounting only for the self-weight of the building. Other factors, however, have to be taken into account to understand the origin of some cracks, which could not be accounted for otherwise. For instance, at the ground floor in sectors $\mathrm{S} 4$ and $\mathrm{S} 5$, the computed maximum tensile stresses are of the same order and quite low $\left(0.06-0.07 \mathrm{~N} / \mathrm{mm}^{2}\right)$. Whereas sector S5 is actually nearly undamaged, this is not the case with sector S4. A reason for the crack pattern in this sector might be the demolition of a nearby chapel at the beginning of the 20th century. Also, the collapse of the bell-tower in 1688 might have aggravated the crack pattern in sector S5 at the level of the women's gallery. These remarks are meant to emphasise that the changes that the Basilica has suffered cannot be forgotten in the interpretation of the present damage pattern.

A key factor that affects the state of stress in the Basilica is the subsidence of the ground. It was already mentioned that ground settlements are not uniform, and an average rotation of the building north-westwards was determined by the monitoring system. This trend is likely to have consistently progressed during the centuries, as a difference in height of about $0.12 \mathrm{~m}$ exists at the ground level between the apsidal zone and the opposite side rising towards the apse (Figure 3a). The effect of the ground settlements and their probable time evolution are investigated elsewhere (Taliercio and Binda, 2006).

Numerical analyses will be carried out assuming a nonlinear constitutive law for masonry to try and fully explain the crack pattern and the effectiveness of the iron rods. As nonlinear analyses are extremely time-demanding, some sub-structures will be singled out from the complete finite element model and individually analysed, exploiting the results of the analysis presented here to prescribe correct boundary conditions to the parts of model considered.

Taking the foregoing remarks into account, it can be concluded that a linear elastic structural analysis of the considered Basilica can explain most of the observable local 
faults and gives information on the displacement field in agreement with available measurements. The same remarks are likely to apply, with due caution, to other historical masonry buildings in different regions.

\section{Acknowledgements}

The authors are indebted to Mrs Anna Pasta who developed the finite element model of the Basilica and performed the numerical analyses presented here. The assistance of the Monuments and Fine Arts Office of Ravenna in the research is also acknowledged. Most of the historical data were taken from the PhD Thesis of Dr Nora Lombardini whose invaluable contribution is gratefully acknowledged by the authors.

\section{References}

Binda, L., Lombardini, N. and Guzzetti, F. (1995) 'San Vitale in Ravenna: a survey on materials and structures', in Historische Bauwerke - Konstruktiv sichern, behutsam konservieren schonend nutzen, Internationale Tagung des SFB 315, Karlsruhe (D), pp. 113-124.

Binda, L., Tedeschi, C. and Baronio, G. (1999) 'Mechanical behaviour at different ages, of masonry prisms with thick mortar joints reproducing a Byzantine masonry', Proceedings of the 8th North American Masonry Conference, University of Austin, TX, (USA), CD-ROM.

Deichmann, F.W. (1969-1976) 'Ravenna, Hauptstadt des spätantiken Abendlande (in German)', 3 volumes, Franz Steiner Verlag, Wiesbaden (D).

Lombardini, N. (1997) Contribution to the Knowledge of St. Vitale's Basilica in Ravenna: Building Technique, Materials, Structure (in Italian) PhD Thesis, Politecnico di Milano.

Lourenço, P.B. (2002) 'Computations on historic masonry structures', Progress in Structural Engineering and Materials, 4(3), 301-309.

Mirabella-Roberti, G., Lombardini, N. and Falter, H. (1995) 'Later Roman domes in clay tubes: historical and numerical study of S. Vitale in Ravenna', Proceedings of the IASS International Symposium on Spatial structures: heritage, present and future, Milan, pp. 1237-1244.

Taliercio, A. and Binda, L. (2006) 'The Basilica of San Vitale in Ravenna: investigation on the current structural faults and their mid-term evolution', Journal of Cultural Heritage, in press. 